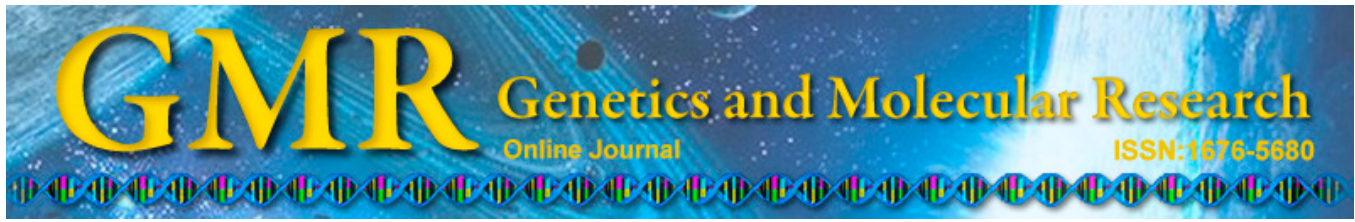

\title{
In vitro differentiation of sperm from male germline stem cell
}

\author{
P. Zheng, X.W. Zhao, X.M. Zheng, A. Khalid, Q. Zhao and G.X. Zhang
}

College of Animal Science and Technology,

Northeast Agricultural University, Harbin, China

Corresponding author: G.X. Zhang

E-mail: gxzhang@neau.edu.cn

Genet. Mol. Res. 14 (2): 2964-2969 (2015)

Received May 19, 2014

Accepted October 17, 2014

Published April 10, 2015

DOI http://dx.doi.org/10.4238/2015.April.10.5

\begin{abstract}
In this study, we developed a model of sperm in vitro differentiation to study the mechanism of spermatogenesis. We isolated newborn male germ cells for in vitro differentiation. We found that after 4-5 weeks of culture, sperm-like cells were occasionally observed in cell co-culture and the feed-layer. After 1-2 weeks of culture followed by 4-5 weeks of co-culture, sperm-like cells were observed.
\end{abstract}

Key words: In vitro differentiation; Male germline stem cell; Neonatal bull; Sperm 


\section{INTRODUCTION}

Spermatogenesis is a complicated cell proliferation and differentiation process based on spermatogonial stem cells, including migration of spermatogonial stem cells, mitosis and proliferation of spermatagonial cells, meiosis of spermatocytes, and metamorphosis of sperm cells. Spermatogonial stem cells are the only cells in animals that can pass genetic information, reproduce on their own, and differentiate into sperm cells. Kanatsu-Shinohara et al. (2003) first successfully cultured spermatogonial stem cells. Studies of the pluripotency of spermatogonial stem cells are important for analyzing cell reprogramming. However, development of in vitro culture systems of spermatogonial stem cells for studying the mechanism of differentiation has progressed slowly.

In this study, we isolated male germ cells and cultured the cells for in vitro differentiation to establish a system for male germ cell differentiation. This system can be used as an in vitro model for studying the mechanism of spermatogenesis.

\section{MATERIAL AND METHODS}

\section{Collection of testes}

The testes of newborn healthy Dutch Friesi calves were provided by Company of Harbin modern biological science and technology which produce calf serum (located in Harbin, Heilongjiang Province, China) The hypogastrium of calf was disinfected with iodine, cut open and testes were collected. The testes were sterilized and their fat pads were removed. Then the testes were washed with $37^{\circ} \mathrm{C}$ saline, placed in $4^{\circ} \mathrm{C}$ saline and returned to the lab within $2 \mathrm{~h}$. The cells were prepared well from testes within $24 \mathrm{~h}$ after the calves were sacrificed by bleeding.

\section{Laboratory reagent}

DMEM/F-12 and fetal bovine serum were purchased from Gibco (Grand Island, NY, USA). Other standard reagents were purchased from Sigma (St. Louis, MO, USA).

The culture medium of differentiation consists of DMEM/F-12, 2\% serum, $2 \mathrm{mM}$ glutamine, $0.1 \mathrm{mM} \beta$-mercaptoethanol, 1\% double anti-MEM non-essential amino acid solution, $1 \%$ MEM vitamin solution, $15 \mu \mathrm{g} / \mathrm{mL}$ insulin-transferrin-sodium selenite, $30 \mu \mathrm{g} / \mathrm{mL}$ sodium pyruvate, $0.05 \mathrm{IU} / \mathrm{mL}$ r-follicle-stimulating hormone and $10^{-6} \mathrm{M}$ testosterone.

\section{Co-culture of male germ cells and Sertoli cells}

The spermatogenic cells suspension was prepared and male germ cells were isolated as described previously (Peng et al., 2013), i.e., one step of different adherence selection method was used. The spermatogenic cell suspension was cultured overnight in $2 \%$ serum-containing culture medium; the supernatant culture medium of Petri dish was collected and centrifuged. After centrifugation, the sediment was washed and resuspended to a density of $1-5 \times 10^{5}$ cells/ $\mathrm{cm}^{2}$ and cultured in $2 \%$ serum-containing culture medium with culture conditions of $5 \% \mathrm{CO}_{2}$, $34^{\circ} \mathrm{C}$ and saturated humidity. By means of the 1-step of different adherence selection method, male germ cells constituted approximately $70 \%$ of the mixed cell population in culture medium. 


\section{Feed layer culture male germ stem cells}

To prepare and separate the spermatogenic cell suspension, we used a previously described method (Peng et al., 2013), i.e. the 2- step of different adherence selection method was used. Ten percent serum-containing culture medium was used to culture cells for 2-4 in the first step of different adherence selection. Then the culture continued overnight for 1-2 days until the samotic cells of the testes had covered the bottom of the culture plate in the second step of different adherence selection. The 2-step method was used to obtain more than $90 \%$ male germline stem cells in the culture medium. The cells were collected by centrifugation, washed with $2 \%$ serum-containing medium, and then resuspended to a cell density to $1-5 \times 10^{5}$ cells $/ \mathrm{cm}^{2}$. The cells were inoculated into a calf sertoli cell feeder layer and incubated in 5\% $\mathrm{CO}_{2}$ at $37^{\circ} \mathrm{C}$ until all the male germ stem cells were adherent. They were then placed in $5 \%$ $\mathrm{CO}_{2}$ at $34^{\circ} \mathrm{C}$ for further culturing.

\section{Male germ stem cell subculture}

The spermatogonial stem cell suspension was prepared and the cells were separated and purified using collagenase digestion as previously described (Peng et al., 2012). Cells were collected by centrifugation, washed with $2 \%$ serum-induced differentiation cell suspension culture medium, and cell density was adjusted to $1-5 \times 10^{5}$ cells $/ \mathrm{cm}^{2}$. The cells were inoculated on the calf Sertoli cell layer to induce differentiation. Culture conditions were 5\% $\mathrm{CO}_{2}, 34^{\circ} \mathrm{C}$, and saturated humidity for 2 days before incubation with $10^{-7} \mathrm{M}$ retinoic acid.

\section{RESULTS}

\section{Co-culture method}

Early in the cultivation process, Sertoli cells became adherent, attached to spermatogonial stem cells, and over time the support cells gradually covered bottom of the culture dish. Spermatogonial stem cells grew to fill in the gaps. After 4 weeks, we occasionally observed dish-like cells (Figure 1A) and elongated sperm-like (Figure 1B) cells. Over time, most of the Sertoli cells gradually became multilayered, stacked, and had detached from the bottom of the culture dish.

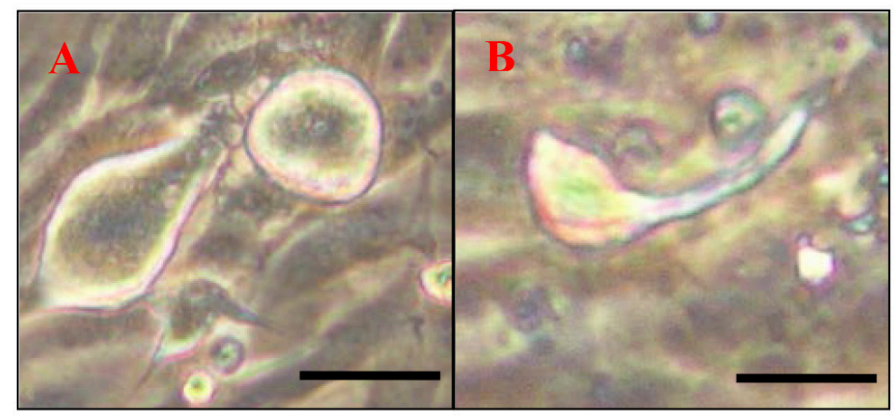

Figure 1. Differentiated spermatoblast. A. Dish-like and deforming cells. B. Elongated sperm-like cells. Bar $=10 \mu \mathrm{m}$. 
During cell culture, we observed that the Sertoli cells had grown into a multilayer and formed seminiferous tubule-like structures (Figure 2A and B), with spermatogonial stem cells over this layer. Some cells formed basement membrane-like structures (Figure 2C), while some sperm-like cells were in the center of seminiferous tubule-like structures (Figure 2D).
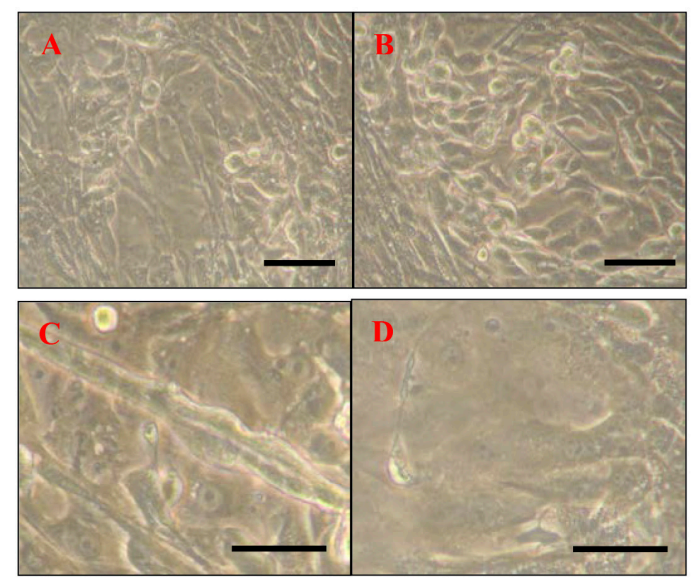

Figure 2. Structure of seminiferous tubules. A. B. Seminiferous tubule-like structure, C. basement membrane-like structures, D. sperm-like cells in the center of seminiferous tubule-like structure. Bar $=50 \mu \mathrm{m}$.

\section{Feed layer method}

After 3 weeks, the volume of some cells had increased as observed using a microscope and cells had become spermatocyte-like (Figure 3A). After 4-5 weeks of culture, a small number of cells with round nuclei and acrosomal vesicles were observed (Figure 3B and C). After 5-6 weeks of culture, sperm cells with tails had appeared, with the head attached to the feeder cells and flagella moving in the culture solution (Figure 3D).

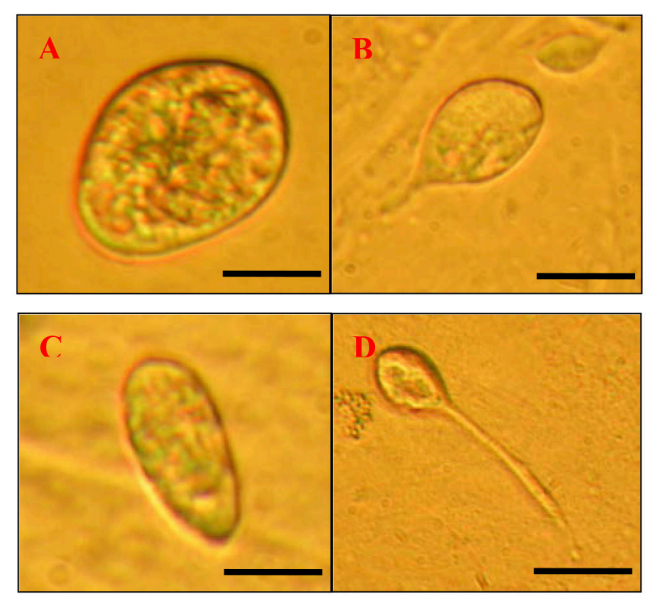

Figure 3. Differentiated spermatoblast. A. Spermatocyte-like cell $(b a r=10 \mu \mathrm{m})$. B. C. Round spermtid-like cell (bar $=10 \mu \mathrm{m})$, D. spermtid-like cell with a tail (bar $=20 \mu \mathrm{m})$. 


\section{Subculture method}

After 1-2 weeks, the cytoplasmic bridge between cells of clusters (Figure 4A), differentiation of spermatocytes classes (Figure 4B), and sperm-like cells were observed (Figure 4C). After 4-5 weeks, sperm-like cells were observed (Figure 4D and E).

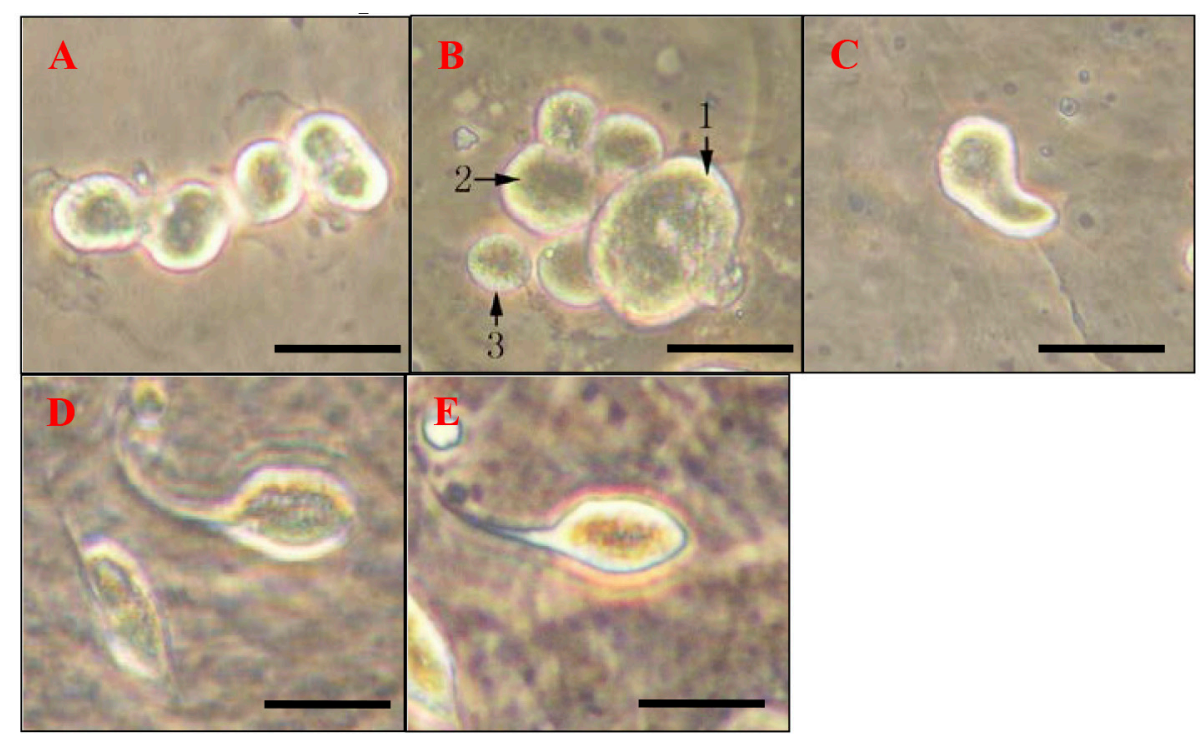

Figure 4. Differentiated spermatoblast. A. Cytoplasmic bridge between cells (bar $=10 \mu \mathrm{m})$, B. differentiation of spermatocytes $(1=$ Primary spermatocyte-like cell, $2=$ secondary spermatocyte-like cell, $3=$ round sperm-like cell, bar $=10 \mu \mathrm{m})$, C. sperm-like cell with a tail $(\mathrm{bar}=10 \mu \mathrm{m})$, D. E. sperm-like cells with a tail $(\mathrm{bar}=20 \mu \mathrm{m})$.

\section{DISCUSSION}

Numerous studies have examined spermatogenic cell differentiation in vitro since the 1960s. Although in vitro spermatogenesis has not been achieved, substantial progress has been made. Tres et al. (1998) proposed that germ cells and Sertoli cells can differentiate only when they are in close contact, and Sertoli cells provide a microenviroment required by the germ cell to maintain the blood-testis barrier. Additionally, various nutrients secreted have an important effect on the development of germ cells. In recent years, various studies have examined the in vitro differentiation of male germ stem cells using a variety of culture systems.

Because of differences in culture methods and conditions, the time required for differentiation of sperm cells may be different. In some studies primary spermatocytes and Sertoli cells were cultured in vitro and induced by follicle-stimulating hormone and testosterone (Dong et al., 2007; Yuncheng et al., 2009). Primary spermatocytes completed meiosis twice, differentiating into early round sperm cells in no longer than 4-6 days. Round sperm cells differentiated (including flagellated and without flagella) and gave birth to normal mice after mature oocyte microinjection (Marh et al., 2003). Up to now, the mature sperm of bovine in vitro culture has not been produced to fertilize ova successfully. So in order to obtain mature sperm in vitro, it is impotant to provide the suitable enviroment such as culture time, culture 
temperature, hormones, inducing factors and the ways of germ cell contacting Sertoli cell. This study demonstrated that at the culture temperature of $34^{\circ} \mathrm{C}$, Sertoli cell feeder layer and culture medium with follicle-stimulating hormone, testosterone and retinoic acid were benefit to differentiation induction of male germ stem cells.

Cells with flagellum were observed after 5 weeks and were suspected to be round sperm-like cells. Although this system can induce the formation of sperm-like cells, the system still requires improvement. Five weeks are required to obtain suspected round sperm-like cells under the experimental conditions used in this study, which is much shorter compared to the time required in vivo.

During the cultivation process, round spermatids free on the surface of adherent cells had short flagellum and produced concentrated cytoplasm, formed amorphous cells, and were not adherent because they had undergone apoptosis or were dead. The sperm cells were implanted into Sertoli cells and showed morphological differentiation, formed fusiform elongated spermatids or sperm cells with only a long flagellum. Fusiform elongated spermatids were observed infrequently, while sperm cells with long flagella were frequently observed in this culture system. This indicates that morphodifferentiation of the round spermatid requires Sertoli cell gap junction communication. After dissociation, interruption of this communication prevents morphodifferentiation.

\section{CONCLUSIONS}

After 4-5 weeks cultured, sperm-like cells were occasionally observed in the cell coculture and feed-layer. After 1-2 weeks of culture, followed by 4-5 weeks of continued culture, we observed sperm-like cells.

\section{ACKNOWLEDGMENTS}

Research supported by the Scientific Research Foundation for Doctors, Northeast Agricultural University (\#2012RCB27), and Open Projects of Key Laboratory of Animal Genetics, Breeding and Reproduction, College ofHeilongjiang Province(\#GXZDSYS-2012-07).

\section{REFERENCES}

Dong WZ, Shen WZ, Hua L and Dou ZY (2007). Study on pluripotency and cultivation of ES-like cells derived from male germ stem cells of bovine fetuses. Chin. J. Biotechnol. 23: 751-755.

Kanatsu-Shinohara M, Ogonuki N, Inoue K, Miki H, et al. (2003). Long-term proliferation in culture and germline transmission of mouse male germline stem cells. Biol. Reprod. 69: 612-616.

Marh J, Tres LL, Yamazaki Y, Yanagimachi R, et al. (2003). Mouse round spermatids developed in vitro from preexisting spermatocytes can produce normal offspring by nuclear injection into in vivo-developed mature oocytes. Biol. Reprod. 69: 169-176.

Peng Z, Lei Y, Yaguang T, He H, et al. (2012). Isolation, purification and culture of male germline stem cells from neonatal bovine testis. J. Northeast Agric. Univ. 12: 32-38.

Peng Z, Pengfei H, Yaguang T, He H, et al. (2013). Isolation, purification and cryopreservation of cells from neonatal bovine testis. J. Northeast Agric. Univ. 1: 37-42.

Tres LL, Mochida K and Kierszenbaum AL (1998). Isolation of the rat spermatid manchette and its perinuclear ring. Dev. Biol. 200: 46-56.

Yuncheng Z, Hong D and Jingbo C (2009). Differentiation of bovine male germ-line stem cells in vitro. Chin. J. Biotechnol. 25: $287-291$. 